\title{
Preparation and Characterization of Superhydrophobic Modification of Polyvinylidene Fluoride Membrane by Dip-Coating
}

\author{
YingNa Li ${ }^{\mathrm{a}, \mathrm{b}, \mathrm{c}}$, HuaFeng Zhang ${ }^{\mathrm{d}}$, Hui Ye ${ }^{\mathrm{a}, \mathrm{c}}$, YuZhong Zhang ${ }^{\mathrm{a}, \mathrm{c},{ }^{*}}$, Ying Chen ${ }^{\mathrm{e}}$ and Yue Li ${ }^{\mathrm{b}}$ \\ ${ }^{a}$ State Key Laboratory of Hollow Fiber Membrane Materials and Processes, Tianjin Polytechnic University, \\ Tianjin 300387, P. R. China \\ ${ }^{b}$ Department of Environmental and Chemical Engineering, Tangshan College, Tangshan 063000, P. R. China \\ ${ }^{c}$ School of Materials Science and Engineering, Tianjin Polytechnic University, Tianjin 300387, P. R. China \\ ${ }^{d}$ Yantai Zhouneng Battery Material Co., LTD (Yantai), Yantai 264000, P. R. China \\ ${ }^{e}$ The Institute of Seawater Desalination and Multipurpose Utilization, SOA (Tianjin), Tianjin 300192, P. R. \\ China
}

\begin{abstract}
The superhydrophobicity polyvinylidene fluoride (PVDF) membranes were modified via reducing surface energy by dip-coating perfluoroalkyl methacrylic copolymer (Zonyl 8740) onto the membranes prepared on mat glass. The chemical component of the unmodified and modified PVDF membranes surface was investigated by ATR-FTIR. Morphology and hydrophobicity of the unmodified and modified PVDF membranes were examined by scanning electronic microscopy and water contact angle, respectively. The effects of concentration of Zonyl 8740, coating time, conditions of heat treatment on hydrophobic capability of PVDF membranes were investigated. The results showed that the water contact angle increased from $141^{\circ}$ to $151^{\circ}$ by the dip-coating modification, therefore getting superhydrophobic PVDF membrane. Moreover, the porosity and the morphology of modified PVDF membrane were unchanged by the dipcoating modification. This results suggested that the hydrophobicty stability of the modified PVDF membrane was also good.
\end{abstract}

Keywords: Polyvinylidene fluoride, Superhydrophobic, Coating modification, Perfluoroalkyl methacrylic copolymer, Membrane preparation.

\section{INTRODUCTION}

In recent years, a great interest attention has been directed to the superhydrophobic surfaces due to the conceivable application in micro fluidics system, surface self-cleaning, material biocompatibility and so on [1-3]. During the last decades, much more research has been devoted to superhydrophobic membranes for using in many of novel applications such as membrane distillation [4], membrane absorption [5-6], membrane self-cleaning [7] and membrane fouling control [8-9].

Therefore, lots of different techniques including plasma etching [10], chemical vapor deposition [11], sol-gel methods [12], electrospinning [13-14], phase separation and plasma treatment [16], have been developed to make superhydrophobic membranes. These methods mainly depend on two ideas: one is making a roughness surface on a low surface energy material; the other is modifying a rough surface with a material of low surface energy [14].

PVDF is a popular material in membrane application due to its advantages such as excellent mechanical

*Address correspondence to this author at the State Key Laboratory of Hollow Fiber Membrane Materials and Processes, Tianjin Polytechnic University, Tianjin 300387, P. R. China; Tel: 02283955806; Fax: 02283955806;

E-mail: Zhangyz2004cn@vip.163.com property, easy process ability, exceptional chemical stability and good thermal stability [14]. Hence, with the superhydrophobic property, the PVDF membranes will be able to be used more widely in the future.

Fluorinated polymers are regarded as low surface energy materials owing to its repellent property for oil and water [17]. Perfluoroalkyl methacrylic copolymer (Zonyl 8740 ) is a kind of cationic fluoride, and can be used to obtain super water-repellent films [18-19]. Farhadi prepared the anti-ice surface by spin-coating Ag nano-particles and subsequently dip-coating with a thin film of Zonyl 8740 [20]. Hsieh fabricated superhydrophobic carbon fabric by decorating carbon nanotubes onto microsized carbon fibers and subsequent fluorination surface treatment [21].

In our previous study, PVDF hydrophobic membrane was prepared by copying with rough glass, and the WCA of PVDF membrane was $141^{\circ}$ [22]. However, the WCA of the PVDF membrane was less than $150^{\circ}$ and membrane performance was not investigated. This study aims to research the feasibility of obtaining the superhydrophobicity of PVDF membranes simply by coating low surface energy materials (Zonyl 8740) onto the membrane prepared on mat glass. 


\section{EXPERIMENTAL}

\subsection{Materials}

Polyvinylidene fluoride (PVDF), type761A, Arkema (China) Investment Co., Ltd; N,N-Dimethylacetamide (DMAc) (AR), Tianjin Kemiou Chemical Reagent Co., Ltd.; Ethanol (AR), Tianjin Kemiou Chemical Reagent Co., Ltd.; Zonyl 8740, Shanghai Dupont Industrial Co., Ltd.

\subsection{Preparation of PVDF Membranes}

The PVDF powder was dried at $100{ }^{\circ} \mathrm{C}$ under vacuum for $24 \mathrm{~h}$ before used. The PVDF solution (10 wt. \%) with DMAc as the solvent was prepared at $60{ }^{\circ} \mathrm{C}$ for $12 \mathrm{~h}$. The casting solution was placed at $60{ }^{\circ} \mathrm{C}$ for about $24 \mathrm{~h}$ to release the gas bubbles in the casting solution. Then the membranes were obtained with the casting solution on the rough glass, $30{ }^{\circ} \mathrm{C}$ water bath as coagulant for 24 hours and cleaned and dried later.

\subsection{Zonyl 8740 Coating on the Surface of PVDF Membranes}

\subsubsection{Zonyl 8740 Coating Solution Preparation}

Zonyl 8740 solution for coating purpose was prepared by mixing Zonyl 8740 and ultra-pure Milli-Q water at room temperature to form a homogeneous solution. The concentration of Zonyl $8740\left(\mathrm{C}_{\text {Zonyl8740 }}\right)$ was varied from $0.5 \mathrm{wt} . \%$ to $6 \mathrm{wt} . \%$.

\subsubsection{Coating of Zonyl 8740 onto the PVDF Membranes}

The membranes were dip-coated in the coating solutions with different concentration for a predetermined period of time ranging from $0 \mathrm{~h}$ to $50 \mathrm{~h}$. Then the coated membranes were dried in the vacuum, with the time of heat treatment ranging from $1 \mathrm{~h}$ to $8 \mathrm{~h}$ and the temperature of heat treatment ranging from $30{ }^{\circ} \mathrm{C}$ to $110{ }^{\circ} \mathrm{C}$. At last the membranes were rinsed and dried. These membranes were labeled as modified PVDF membranes.

\subsection{Membrane Characterization}

\subsubsection{Scanning Electron Microscopy (SEM)}

SEM images were taken by the Hitachi s-4800 Scanning Electron Microscope operated at $5 \mathrm{kV}$. Before collecting the SEM images, all samples of PVDF membranes were coated with gold.

\subsubsection{Water Contact Angle Measurement (WCA)}

Static WCA were tested with the JYSP-180 optical water contact angle measuring device at room temperature. A droplet of single $5 \mu \mathrm{L}$ ice water was used as the measure droplet. All the WCA data were averaged with five measurements to minimize experimental errors at different locations of membrane surface.

\subsubsection{Fourier Transformed Infrared Spectroscopy (ATR-FTIR)}

The properties of the unmodified and modified PVDF membranes were analyzed with ATR-FTIR (TENSOR37). The surface infrared spectra of the unmodified and modified PVDF membranes were collected between $400 \mathrm{~cm}^{-1}$ and $4000 \mathrm{~cm}^{-1}$.

\subsubsection{Membrane Porosity}

Membrane porosity $(\varepsilon)$ was obtained by gravimetric method. Some dry membranes were placed into ethanol at room temperature for $24 \mathrm{~h}$ in order to fill the pores with ethanol completely. Then, the ethanol out side of the membranes was removed by rubbing away and the weight of the wet membranes $\left(W_{w}\right)$ was measured. After the membranes were dried, the weight of dried membranes $\left(W_{d}\right)$ was measured. $\varepsilon$ was calculated by Eq. (1).

$\varepsilon=\frac{W_{w}-W_{d}}{S \times d \times \rho} \times 100 \%$

Where $S$ is represented as the area of the membrane $\left(\mathrm{cm}^{2}\right)$; $d$ is used as the thickness of the membrane $(\mathrm{cm})$; the ethanol density is represented by $\rho\left(0.789 \mathrm{~g} / \mathrm{cm}^{3}\right)$.

\subsubsection{The Hydrophobicity Stability of Modified PVDF Membrane}

The modified PVDF membranes were fully immersed into de-ionized water and alcohol respectively at different time (from $0 \mathrm{~h}$ to $24 \mathrm{~h}$ ). Then the membranes were brought out of the solvents, cleaned in pure water and dried by vacuum after predestined time. And the static WCA of the modified PVDF membranes was tested.

\section{RESULTS AND DISCUSSION}

3.1. Effects of Modification Condition on Hydrophobicity of Modified PVDF Membranes

\subsubsection{Effect of Coating Time on Hydrophobicity}

The figure indicates that as the coating time increases, the WCA of modified PVDF membranes approaches the maximum $\left(144^{\circ}\right)$, and then does not change (Figure 1). The WCA of the modified PVDF 


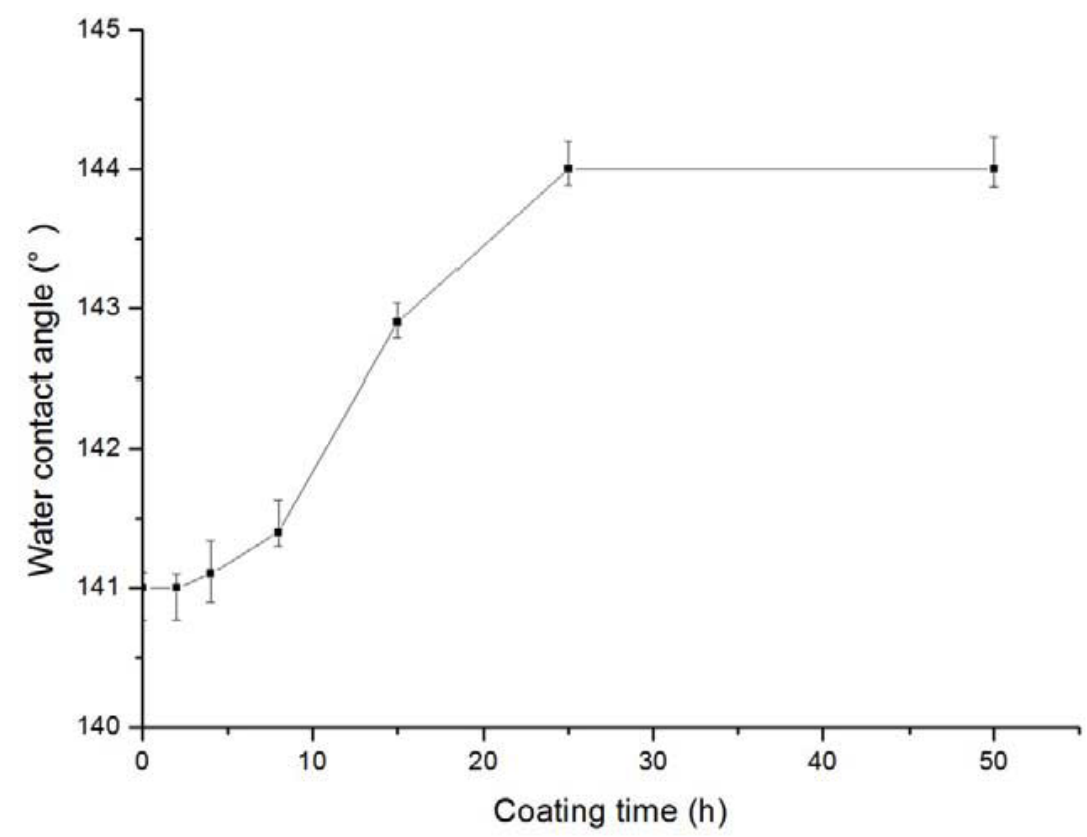

Figure 1: Effect of coating time on the hydrophobicity (Zonyl 8740 concentration was $2 \mathrm{wt} . \%$, the temperature of heat treatment was $\left.30^{\circ} \mathrm{C}\right)$.

membranes is stable with the coating time less than $8 \mathrm{~h}$ or greater than $25 \mathrm{~h}$, while the change of the WCA of the modified PVDF membranes is obvious when the coating time is from $8 \mathrm{~h}$ to $25 \mathrm{~h}$. This fact may be explained that with the coating time increasing from beginning to $25 \mathrm{~h}$, the degree of modify is saturated, which results in decreasing the surface energy of modified PVDF membranes and increasing the WCA of the modified PVDF membranes.

\subsubsection{Effect of Heat Treatment on Hydrophobicity}

The WCA of the modified PVDF membranes increases with the increase of the heat treatment temperature from $30{ }^{\circ} \mathrm{C}$ to $100{ }^{\circ} \mathrm{C}$. And the dependence of the time of heat treatment on the WCA of the modified PVDF membranes shows that with the time of heat treatment extending from $1 \mathrm{~h}$ to $8 \mathrm{~h}$ the WCA of the modified PVDF membranes becomes bigger (Figure 2). It is because the adhesion between PVDF membrane

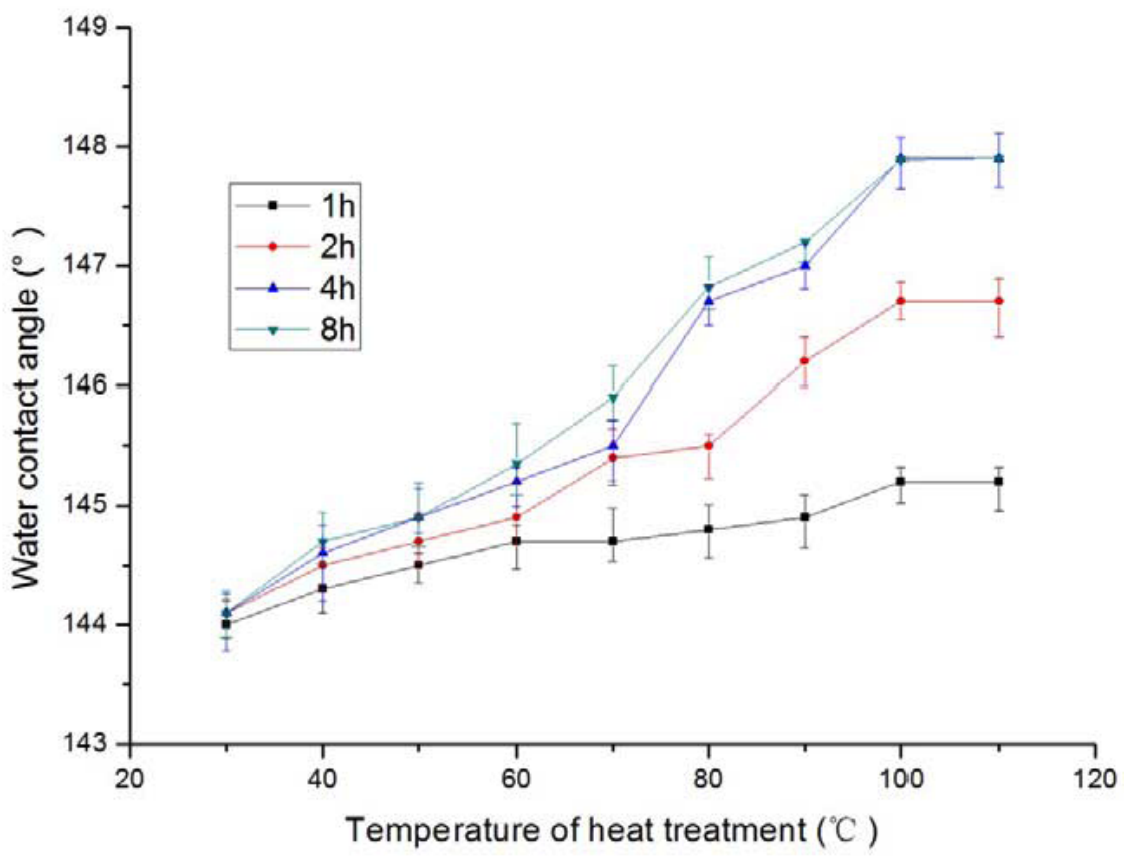

Figure 2: Effect of heat treatment on the hydrophobicity (Zonyl 8740 concentration was $2 \mathrm{wt} . \%$, the coating time was $25 \mathrm{~h}$ ). 


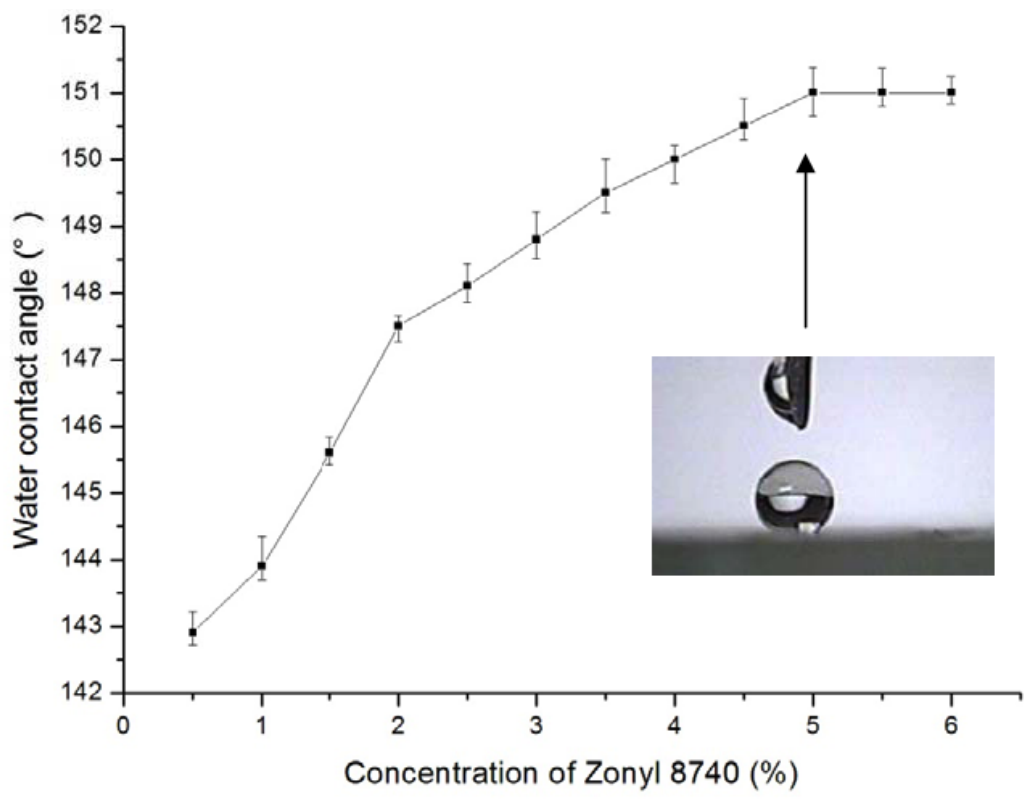

Figure 3: Effect of the concentration of Zonyl 8740 on the hydrophobicity (the coating time was $25 \mathrm{~h}$, the time of heat treatment was $4 \mathrm{~h}$, the temperature of heat treatment was $100^{\circ} \mathrm{C}$ )

and Zonyl 8740 is stronger as the temperature of heat treatment is higher or the time of heat treatment is longer, and $100{ }^{\circ} \mathrm{C}$ of heat treatment temperature, $4 \mathrm{~h}$ of heat treatment time are choose as the heat treatment conditions. It is similar to the results reported by Farhadi and Hsieh [20,23].

\subsubsection{Effect of Concentration of Zonyl 8740 on Hydrophobicity}

The influence of the concentration of Zonyl8740 $\left(\mathrm{C}_{\text {Zonyl8740 }}\right)$ on the hydrophobicity of the modified PVDF membranes is shown in Figure 3. It reveals that the effect of $\mathrm{C}_{\text {Zonyl8740 }}$ on the hydrophobicity of the modified PVDF membranes is notable. With $\mathrm{C}_{\text {Zonyl8740 }}$ ranging from $0.5 \mathrm{wt} . \%$ to $6 \mathrm{wt} . \%$, the WCA of PVDF membranes increased from $141^{\circ}$ for virgin PVDF membranes to the maximum WCA with $151^{\circ}$ (at $\mathrm{C}_{\text {Zonyl8740 }}=(5 \mathrm{wt} . \%)$ ) (Figure 3 ). It is noted that $\mathrm{C}_{\text {Zonyl8740 }}$ with $5 \mathrm{wt}$. \% is enough, and it is not useful to use much high concentration of Zonyl8740 to decline the surface energy of PVDF membranes, only resulting in depositing on the surface of the modified PVDF membranes uselessly.

\subsection{Membrane Performance}

\subsubsection{Morphology of Membranes}

The top-surface, bottom-surface and cross-sectional structure of the membranes before and after coated with Zonyl 8740 of 5 wt. \% are shown in Figures 4-6. Figure 4 presents the top-surface of PVDF membranes before and after coated with Zonyl 8740 . From Figure 4a1 and $b 1$, the SEM image of the membrane after the modification is similar to the membrane before the modification. As Figure $\mathbf{4 a 2}$ and b2 shown, the pore size of the unmodified PVDF membrane (100-120nm) is bigger than the modified PVDF membrane (90100nm). The PVDF membrane before and after coated with Zonyl 8740 displays a porous structure on the bottom-surface (Figure 5). The cross-section SEM images of PVDF membranes before and after coated with Zonyl 8740 are shown in Figure 6, where the PVDF membranes before and after modification have a finger-like structure near the top-surface and a spongelike and drop shape cavity structure near the bottomsurface (Figs. 6a1 and b1). In fact, the formation of drop shape cavities in the bottom-surface can be related to the slow phase-inversion because of the rough glass substrate [24]. From Figure $\mathbf{6 a 2}$ and b2, the cross-section near top skin layer of the modified PVDF membrane $(600-700 \mathrm{~nm})$ is thicker than the unmodified PVDF membrane (400-500nm), which can be associated to the modification. As Figure $6 \mathrm{a} 3$ and b3 show, there is no difference of the cross-section near bottom skin layer of membranes that before and after coated with Zonyl 8740 . It can be concluded that the morphology of membrane after modification is not altered obviously by the dip-coating modification.

\subsubsection{The Surface Chemical Component Analysis of Unmodified and Modified PVDF Membranes}

The surface chemical component analysis of unmodified and modified PVDF membranes was confirmed by FTIR-ATR. The ATR-FTIR spectra of the 

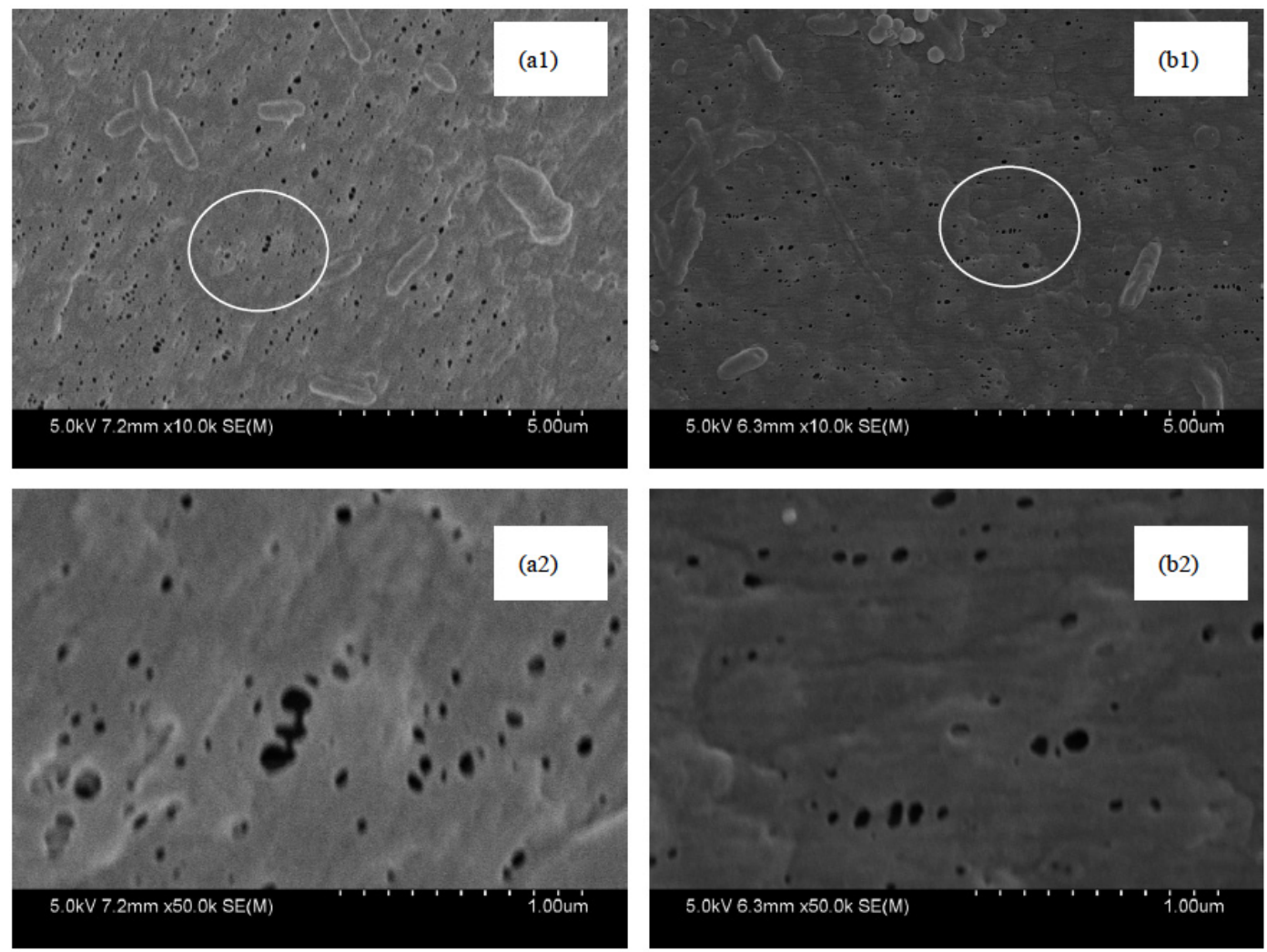

Figure 4: SEM micrographs of top-surface PVDF membranes before and after coated Zonyl 8740: (a) Unmodified PVDF membrane; (b) Modified PVDF membrane; (1) at a magnification of 10,000x; (2) at a magnification of 50,000x.
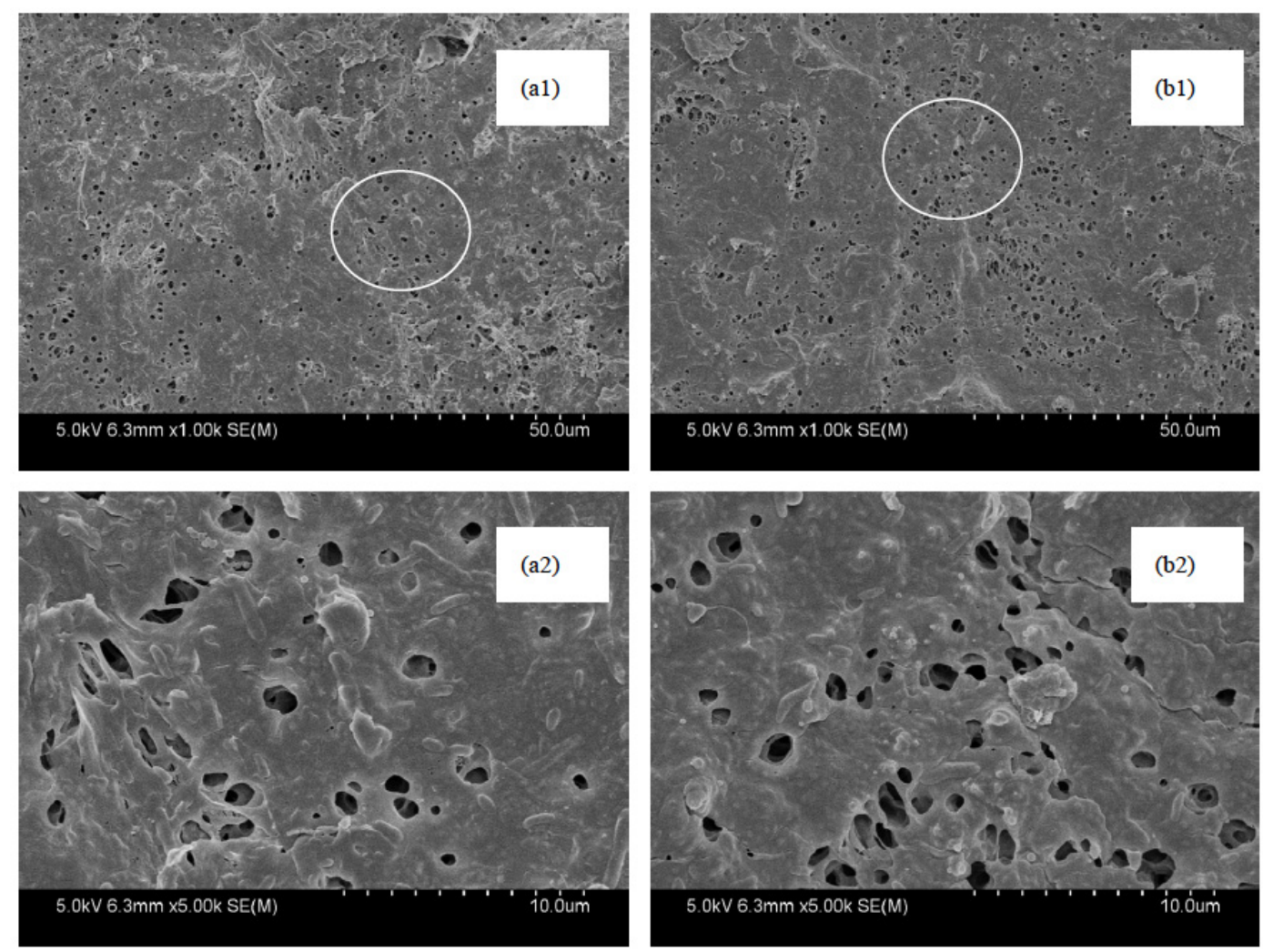

Figure 5: SEM micrographs of bottom-surface PVDF membranes before and after coated Zonyl 8740: (a) unmodified PVDF membrane; (b) modified PVDF membrane; (1) at a magnification of 1,000x; (2) at a magnification of 5,000x. 

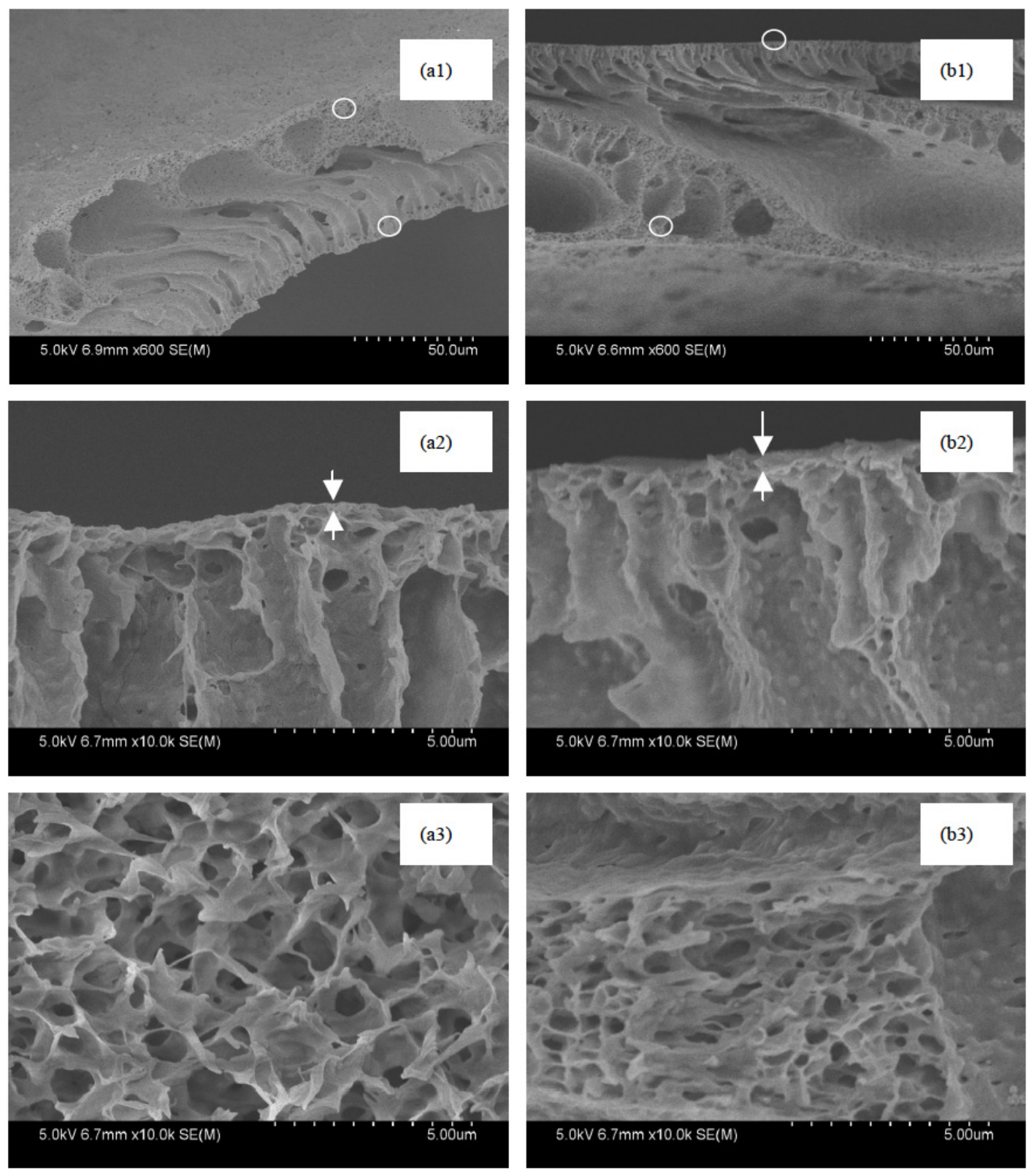

Figure 6: SEM micrographs of cross-section PVDF membranes before and after coated Zonyl 8740: (a) unmodified PVDF membrane; (b) modified PVDF membrane; (1) cross-section; (2) cross-section near top skin layer; (3) cross-section near bottom skin layer.

unmodified and modified PVDF membranes are illustrated in Figure 7. It can be seen that the characteristic peak at $1175 \mathrm{~cm}^{-1}$ corresponds of asymmetrical stretching of $\mathrm{CF}_{2}$. The characteristic peaks at $839 \mathrm{~cm}^{-1}$ and $874 \mathrm{~cm}^{-1}$, and the characteristic peak at $1071 \mathrm{~cm}^{-1}$ represent the amorphous phase and crystal phase of PVDF severally [25]. The absorbance peak observed at $1403 \mathrm{~cm}^{-1}$ represents to the vibration absorption peak of $\mathrm{CH}_{2}$ groups. Compared with the spectra of the unmodified membrane, the new peak at $1732 \mathrm{~cm}^{-1}$ in Figure. $\mathbf{7 b}$ corresponds to the absorption peak of $\mathrm{C}=\mathrm{O}$, which may be caused by dip-coating Zonyl 8740 on membrane. The result confirmed that, there was Zonyl 8740 coated on the modified PVDF membrane surface.

\subsubsection{Effect of Modification on Membrane Porosity}

The gravimetric method was carried out in order to prove that the modification has not substantially changed the membrane porosity [8]. The result reveals that the membrane porosity is not altered significantly after dip-coating of the Zonyl 8740 (Figure 8). It also can be seen by comparing the SEM images in Figures 5 and $\mathbf{6}$, the modification does not significantly change the membrane porosity of the membrane coated by Zonyl 8740. 


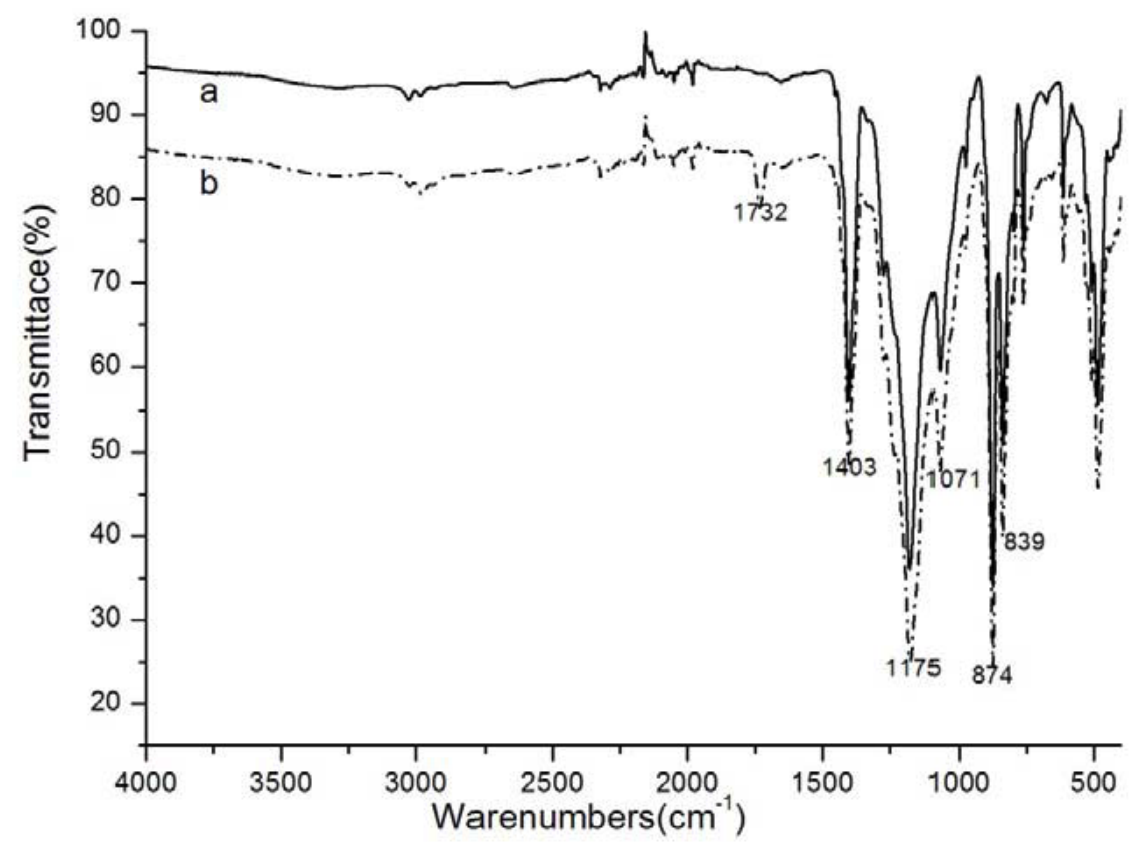

Figure 7: FTIR-ATR spectra of PVDF membranes (a) unmodified membrane; (b) modified membrane.

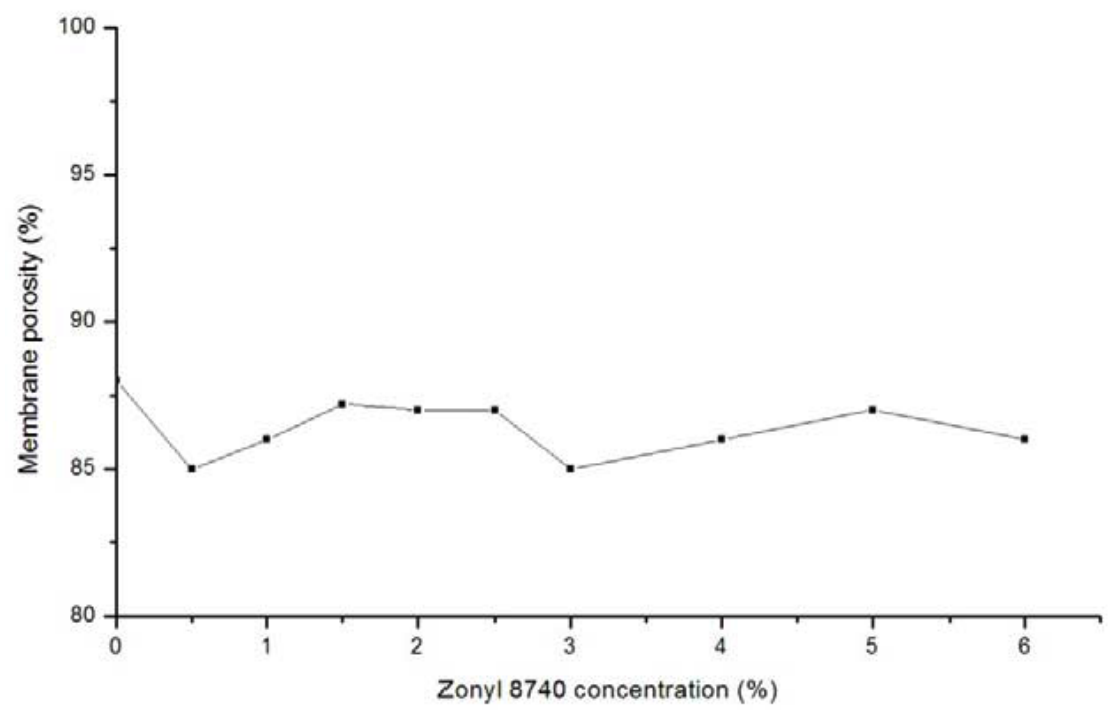

Figure 8: Effect of Zonyl 8740 concentration on PVDF membrane porosity.

\subsubsection{The Hydrophobicity Stability of Modified PVDF Membrane}

Figure 9 shows the variation of WCA on the modified PVDF membrane with immersion period. As can be seen in Figure 9, a slight decline of WCA indicates that the modified PVDF membrane possesses a long stability, since the WCA exceeds $150^{\circ}$ with immersion period for $24 \mathrm{~h}$. Also, the antialcohol ability of modified PVDF membrane is good with immersion period for $24 \mathrm{~h}$ because the WCA is more than $150^{\circ}$. These results confirm (i) the fairly good hydrophobicty stability of Zonyl 8740 and (ii) the strong adhesion between PVDF membrane and Zonyl
8740 after heat treatment. It was also reported that the superhydrophobicty of the surface coated Zonyl 8740 is stable due to the good stability of Zonyl 8740 against ethylene glycol and water [23].

\section{CONCLUSIONS}

The super-hydrophobic PVDF membranes were obtained via reducing the surface energy by coating Zonyl 8740. By controlling the concentration Zonyl 8740 , coating time and heat treatment, the membrane with the WCA of $151{ }^{\circ} \mathrm{C}$ was obtained. The PVDF membrane before coated with Zonyl 8740 exhibited 


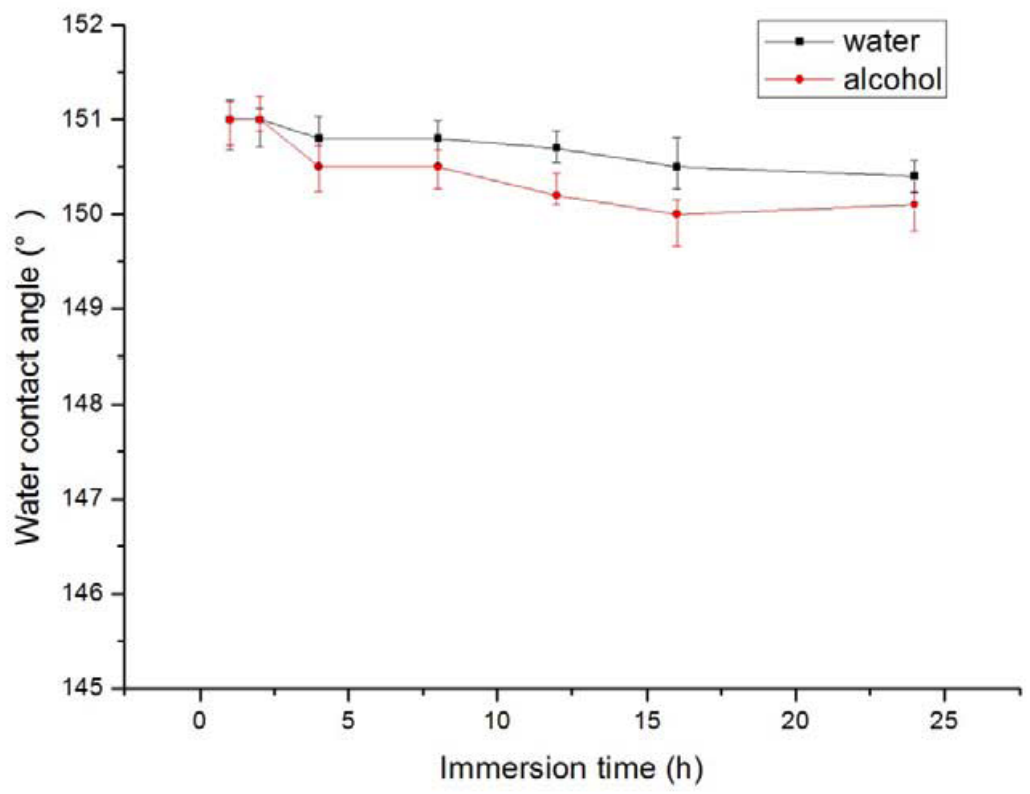

Figure 9: The hydrophobicity stability of modified PVDF membrane.

finger-like structure and displayed a very open pore structure, and the membrane morphology was intact after coated with Zonyl 8740 . The results showed that the modified PVDF membranes also had unchanged membrane porosity and good hydrophobicty stability. The super-hydrophobic PVDF membrane could be obtained by the follow feasible conditions: mat glass of substrate, $10 \%$ of PVDF concentration in casting solution, $100{ }^{\circ} \mathrm{C}$ of heat treatment temperature, $4 \mathrm{~h}$ of heat treatment time and $5 \%$ of Zonyl 8740 as coating solution.

\section{ACKNOWLEDGEMENTS}

This research was sponsored by the National Natural Science Foundation of China (Funding No. 51373120, 50973083, No. 51173132), the Research Fund for the Doctoral Program of Higher Education (Funding No.20111201110003, 20091201120002), the open project of State Key Laboratory of Hollow Fiber Membrane Materials and Membrane Processes, Tianjin Natural Science Foundation of China (No. 11JCZDJC21200, 11JCZDJC23700), Science and Technology Project of Hebei Province (No. 13273707), Tangshan City science and technology research and development program (131302116a, 13110208b) and the Ocean Public Welfare Scientific Research Project, State Oceanic Administration People's Republic of China (201305004-5).

\section{REFERENCES}

[1] Julianna A, Sandra E, Jilska M, Geoff WS. Fabrication of a super-hydrophobic polypropylene membrane by deposition of a porous crystalline polypropylene coating [J]. J Membr Sci 2008; 318:107-10. http://dx.doi.org/10.1016/j.memsci.2008.02.032

[2] Whitesides GM. Self-assembling materials [J]. Scient Am 1995; 9:146-49.

[3] Tiano P, Biagiotti L, Mastromei G. Bacterial biomediated calcite precipitation for monumental stones conservation: methods of evaluation [J]. J Microbiol Methods 1999; 36: 139-45. http://dx.doi.org/10.1016/S0167-7012(99)00019-6

[4] El-Bourawi MS, Ding Z, Ma R, Khayet M. A framework for better under-standing membrane distillation separation process [J]. J Membr Sci 2006; 285: 4-29.

http://dx.doi.org/10.1016/j.memsci.2006.08.002

[5] Lv YX, Yu XH, Jia JJ. Fabrication and characterization of superhydrophobic polypropylene hollow fiber membranes for carbon dioxide absorption [J]. Appl Energy 2012; 90: 167-74. http://dx.doi.org/10.1016/j.apenergy.2010.12.038

[6] Wongchitphimon S, Wang R, Jiraratananon R. Surface modification of polyvinylidene fluoride-co-hexafluoropropylene (PVDF-HFP) hollow fiber membrane for membrane gas absorption [J]. J Membr Sci 2011; 381: 18391. http://dx.doi.org/10.1016/j.memsci.2011.07.022

[7] Wang S, Li YP, Fei XL. Preparation of a durable superhydrophobic membrane by electrospinning poly(vinylidene fluoride) (PVDF) mixed with epoxy-siloxane modified $\mathrm{SiO}_{2}$ nanoparticles: $A$ possible route to superhydrophobic surfaces with low water sliding angle and high water contact angle [J]. J Colloid Interf Sci 2011; 359: 380-88.

http://dx.doi.org/10.1016/j.jcis.2011.04.004

[8] Hendren ZD, Brant J, Wiesner MR. Surface modification of nanostructured ceramic membranes for direct contact membrane distillation [J]. J Membr Sci 2009; 331: 1-10. http://dx.doi.org/10.1016/j.memsci.2008.11.038

[9] Ma Z, Hong Y, Ma L, Su M. Superhydrophobic membranes with ordered arrays of nanospiked microchannels for water desalination [J]. Langmuir 2009; 25: 5446-50. http://dx.doi.org/10.1021/la900494u

[10] Mundo RD, Palumbo F, d'Agostino R. Nanotexturing of polystyrene surface in fluorocarbon plasmas: from sticky to 
slippery superhydrophobicity [J]. Langmuir 2008; 24: 504451. http://dx.doi.org/10.1021/la800059a

[11] Zheng ZR, Gu ZY, Huo RT, Ye YH. Superhydrophobicity of polyvinylidene fluoride membrane fabricated by chemical vapor deposition from solution [J]. Appl Surf Sci 2009; 255: 7263-67.

http://dx.doi.org/10.1016/j.apsusc.2009.03.084

[12] Sun $X D$, Zhang YZ, Li YX, Li H. Preparation of superhydrophobic polyethersulphone membrane by sol-gel method [J]. Adv Mater Res 2009; 839: 79-82.

[13] Ding B, Ogawaa T, Kim J. Fabrication of a Superhydrophobic Nanofibrous Zinc Oxide Film Surface by Electrospinning [J]. Thin Solid Films 2008; 516: 2495-501. http://dx.doi.org/10.1016/j.tsf.2007.04.086

[14] Chen YB, Kim H. Preparation of superhydrophobic membranes by electrospinning of fluorinated silane functionalized poly(vinylidene fluoride) [J]. Appl Surf Sci 2009; 255: 7073-77.

http://dx.doi.org/10.1016/j.apsusc.2009.03.043

[15] Han JT, Xu XR, Cho KW. Diverse access to artificial superhydrophobic surfaces using block copolymers [J]. Langmuir 2005; 21: 6662-65. http://dx.doi.org/10.1021/la051042+

[16] Fresnais J, Chapel JP, Poncin-Epaillard F. Synthesis of transparent super-hydrophobic polyethylene surfaces [J]. Surf Coat Technol 2006; 200: 5296-305. http://dx.doi.org/10.1016/j.surfcoat.2005.06.022

[17] Huang PY, Chao YC, Liao YT. Preparation of fluoroacrylate nanocopolymer by miniemulsion polymerization used in textile finishing [J]. J Appl Polym Sci 2004; 94: 1466-72. http://dx.doi.org/10.1002/app.21054

[18] Bayer IS, Biswas A, Ellialtioglu G. Fabrication of super water repellent silver flake/copolymer blend films and their potential as smart fabrics [J]. Polym Composit 2011; 576-585. http://dx.doi.org/10.1002/pc.21081
[19] Bayer IS, Steele A, Martorana PJ, Loth E, Miller L. Superhydrophobic cellulose-based bionanocomposite films from Pickering emulsions [J]. Appl Phys Lett 2009; 94: 163902-903.

http://dx.doi.org/10.1063/1.3120548

[20] Farhadi S, Farzaneh M, Kulinich SA. Anti-icing performance of superhydrophobic surf aces [J]. Appl Surf Sci 2011; 257: 6264-69.

http://dx.doi.org/10.1016/j.apsusc.2011.02.057

[21] Hsieh CT, Chen WY, Wu FL. Fabrication and superhydrophobicity of fluorinated carbon fabrics with micro/nanoscaled two-tier roughness [J]. Carbon 2008; 46: 1218-24. http://dx.doi.org/10.1016/j.carbon.2008.04.026

[22] Zhang HF, Zhang YZ, Lin LG. Preparation and Characterization of PVDF Hydrophobic Membrane [J]. Adv Mater Res 2011; 221: 338-42. http://dx.doi.org/10.4028/www.scientific. net/AMR.221.338

[23] Hsieh T, Wu FL, Chen WY. Superhydrophobicity and superoleophobicity from hierarchical silica sphere stacking layers [J]. Mater Chem Phys 2010; 121: 14-21.

http://dx.doi.org/10.1016/j.matchemphys.2009.12.031

[24] Ismail AF, Mansourizadeh A. A comparative study on the structure and performance of porous polyvinylidene fluoride and polysulfone hollow fiber membranes for $\mathrm{CO}_{2}$ absorption [J]. J Membr Sci 2010; 365: 319-28. http://dx.doi.org/10.1016/j.memsci.2010.09.021

[25] Zhang J, Song ZY, Li BA, et al. Fabrication and characterization of superhydrophobic poly(vinylidene fluoride) membrane for direct contact membrane distillation [J]. Desalination 2013; 324: 1-9. http://dx.doi.org/10.1016/j.desal.2013.05.018 